\title{
Metastasizing placental site trophoblastic tumor: immunohistochemical and DNA analysis. 2 case reports and a review of the literature
}

\author{
S. Remadi $^{1}$, B. Lifschitz-Mercer ${ }^{2}$, H. Ben-Hur ${ }^{3}$, R. Dgani ${ }^{3}$, B. Czernobilsky ${ }^{3}$ \\ ${ }^{1}$ Institut de Pathologie Clinique, Hôpital Cantonal Universitaire de Genève, \\ 1, rue Michel Servet, CH-1211 Genève 4, Switzerland \\ 2 Institute of Pathology, Sourasky Medical Center, Tel Aviv, Israel \\ (affiliated to the Sackler Faculty of Medicine, Tel Aviv University) \\ ${ }^{3}$ Dept. of Obstetrics and Gynecology, Kaplan Hospital, Rehovot, Israel \\ (affiliated to the Medical School of the Hebrew University and Hadassah, Jerusalem)
}

Received: 19 April 1996 / Accepted: 7 October 1996

\begin{abstract}
Placental-site trophoblastic tumor (PSTT) is a rare form of gestational trophoblastic neoplasia. The clinical behaviour of PSTT is usually benign, but sometimes it can be highly malignant with late recurrence and metastasis. We describe two cases of PSTT with pulmonary metastasis in patients aged 35 and 29 years respectively. The mitotic rate was elevated to 9 and 13 mitotic figures per 10 high-power fields respectively. Immunohistochemical staining showed a predominance of human placental lactogen (hPL) positive cells when compared with human chorionic gonadotropin (hCG) reactive cells in one case, and a reverse pattern in the other one. DNA measurement in one case showed an aneuploid tumor with a tetraploid DNA peak. The clinical behaviour of PSTT remains unpredictable, and there are no reliable means of predicting clinical outcome.
\end{abstract}

Key words: Placental site trophoblastic tumor - Metastasis

\section{Introduction}

Placental site trophoblastic tumor (PSTT) is a rare form of gestational trophoblastic disease; its epidemiology and risk factors are not well known. This neoplasm is composed primarily of intermediate trophoblast and lacks the mixture of cytoand syncytiotrophoblast observed in choriocarcinoma. The histologic appearence echoes the infiltration of the endometrium and myometrium of the placental site [13]. The clinical behaviour of PSTT is usually benign, but can be highly malignant [7]. And there are no reliable histologic, immunohistochemical, or DNA ploidy predictors of clinical outcome $[5,11,13]$. We report two cases of PSTT with pulmonary metastases and malignant outcome. We studied them with immunohistochemical methods and DNA image analysis.

Correspondence to: $\mathrm{S}$. Remadi 


\section{Case report}

\section{Case 1}

A 35 year old woman, gravida 3, para 3, was admitted to the hospital with a history of irregular vaginal bleeding for 6 months. The last delivery of a normal infant was 22 months previously. Six years previously a complete hydatidiform mole had been diagnosed and treated with methotrexate. On admission physical examination revealed an enlarged uterus. Curetage yielded a large amount of soft, haemorrhagic material. Histologic examination showed PSTT within the endometrial fragments. A total hysterectomy with wedge resection of the right ovary and omental biopsy were done. The uterus weighed $200 \mathrm{gr}$ and measured $4 \times 8 \times 11 \mathrm{~cm}$. On gross examination the endometrial mucosa was unremarkable. The lumen contained some bloody material. Within the uterine wall there was a soft whitish area of about $2 \mathrm{~cm}$ with hemorrhagic foci. The cervix, ovarian and omental tissue were unremarkable.

Histologically the curettings and the soft whitish area of the uterine wall showed tumor tissue composed of large rounded or polyhedral intermediate trophoblastic cells, arranged in irregular nests. These cells had variably sized hyperchromatic nuclei, with irregular smudgy chromatin. The cytoplasm was abundant, amphophilic, with well-defined boundaries (Fig. 1 A).

Most tumor cells were mononucleate, but multinucleate cells and giant nuclei were common. Areas of extensive necrosis and fibrinoid material were observed. At the periphery the tumor infiltrated as single cells and small groups of cells dissecting between muscle fibers. Vascular invasion was common. The mitotic index was 13 mitoses per 10 high-power fields (hpf). Endometrial glands were inactive.

The histology of the pulmonary metastasis was similar to that observed in the curettings (Fig. 1 B). Immunohistochemical analyses of the primary tumor showed a strong diffuse positivity for cytokeratin (wide spectrum), whereas a weak positivity was detected for CK 20 and Epithelial Membrane Antigen (EMA). Reactivity to hPL was observed focally in occasional cells (Fig. 2 B), whereas reactivity for hCG predominated (Fig. 2 A). A similar immunoreactivity was observed in the pulmonary metastases. Cellular DNA measurement of the primary tumor by im-

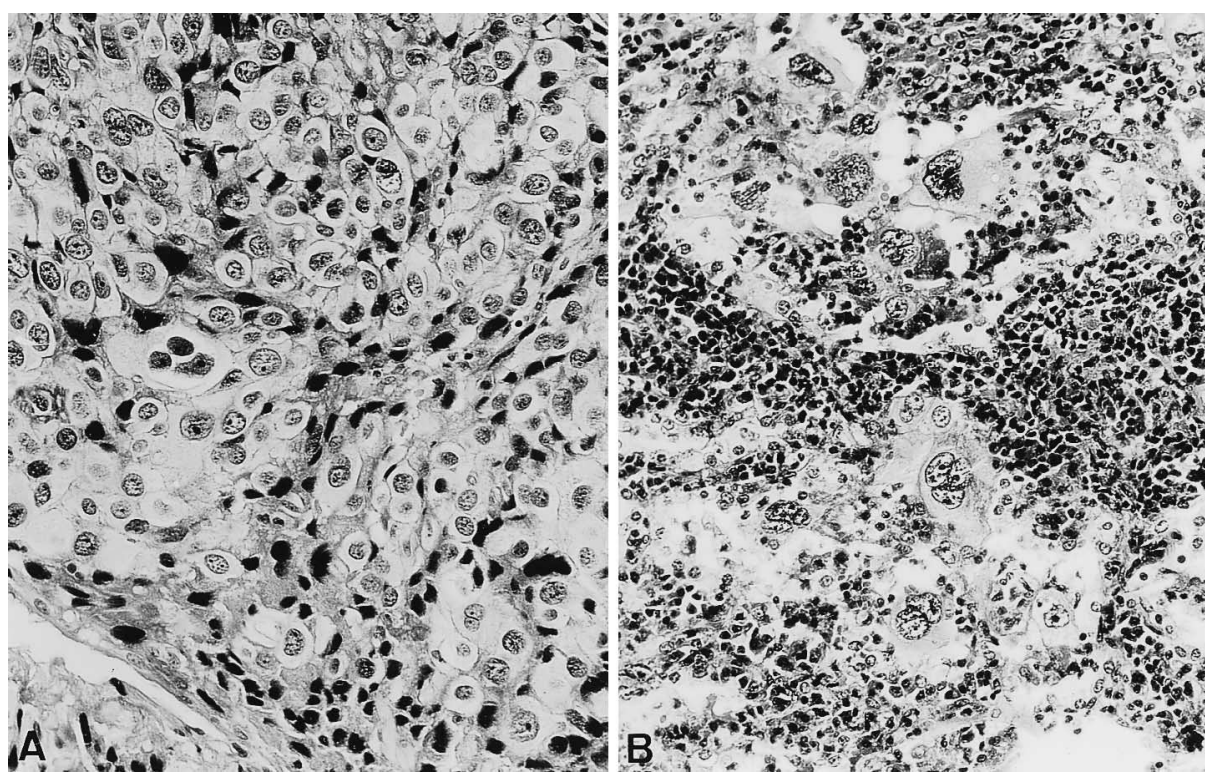

Fig. 1. Case 1: sheets of rounded-to-polygonal pleomorphic intermediate trophoblastic cells (A). (Hematoxylin-eoxin $\times 300$ ). Malignant intermediate trophoblastic cells invading the alveolar lumen $(\mathbf{B})$. (Hematoxylin-eosin $\times 100)$ 

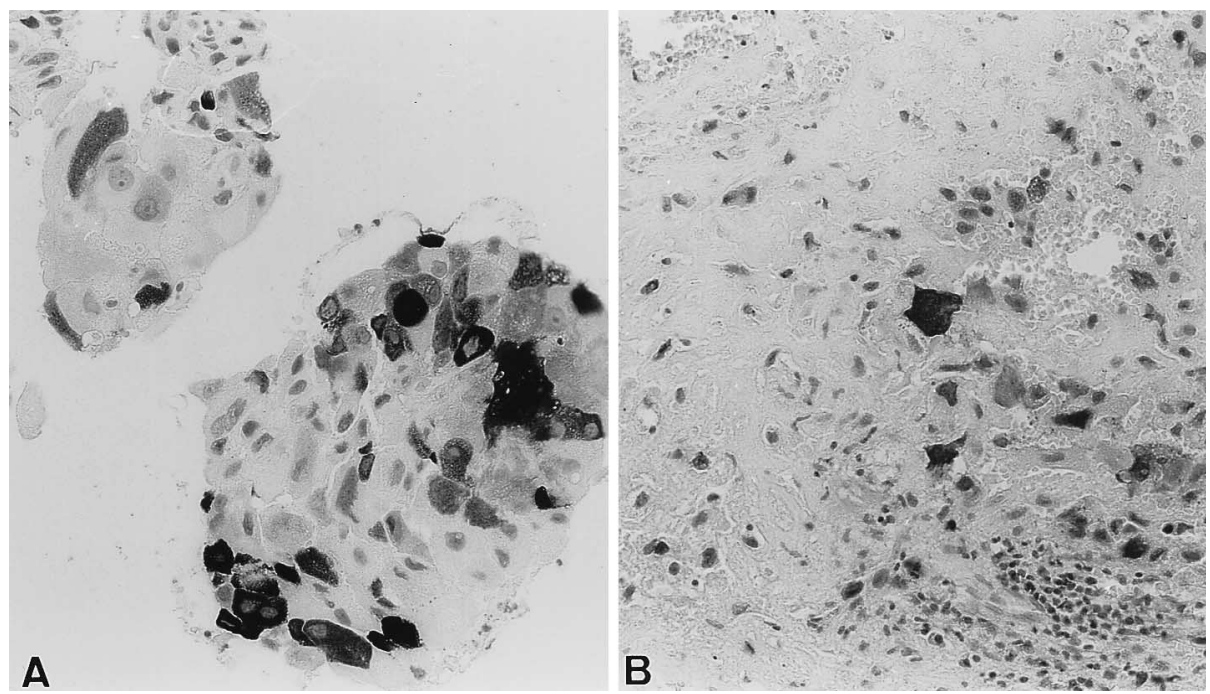

Fig. 2. Case 1: tumor cells reactive with anti-hCG antibody (A) predominate when compared with tumor cells reactive with anti-hPL antibody $(\mathbf{B})$. (Immunoperoxidase $\times 300)$

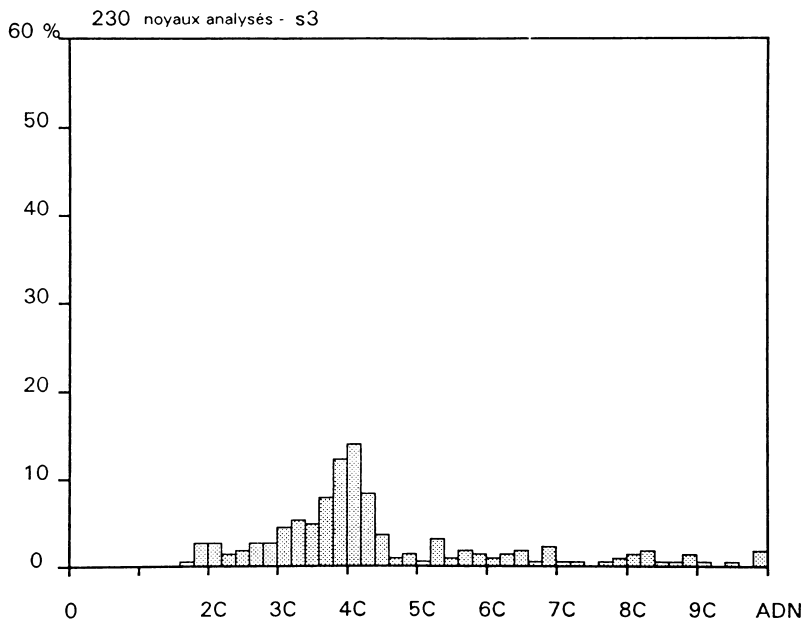

Fig. 3. DNA histogram showing an aneuploid pattern with a tetraploid peak

age analysis showed an aneuploid tumor with a tetraploid DNA peak, and a prominent S-phase fraction (Fig. 3).

Follow-up with hCG serum levels was unremarkable. Eleven months later the patient presented with a right spontaneous pneumothorax and accumulation of a small amount of pleural fluid in the right pleural cavity.

Tomography revealed a small parenchymal infiltrate at the right lung base. Fine needle aspiration of this infiltrate was not diagnostic. An open lung biopsy was performed and a hemorrhagic fragment of tissue of $1.0 \mathrm{~cm}$ in diameter was removed.

The patient received chemotherapy with EMA-Co regimen (VP-16, Actinomycin D, Methotrexate, Folinic acid, Vincristine, Cytoxan) and is at present clinically free of tumor. 


\section{Case 2}

A 29 year old woman, gravida 3, para 3, was admitted to the hospital with irregular vaginal bleeding since her last delivery 4 months previously. Since hCG serum levels remained elevated following the delivery she had been treated for one month with actinomycin with a presumed diagnosis of gestational trophoblastic disease. A tissue diagnosis could not be established at that time. On admission ultrasound examination revealed an irregular lesion of about $2 \mathrm{~cm}$ in diameter in the posterior wall of the uterus.

A total abdominal hysterectomy which included a vaginal segment was performed. The uterus measured $9 \times 6 \times 5 \mathrm{~cm}$ and weighed 120 gr. The external surface and the mucosal lining were grossly unremarkable. The posterior wall of the uterus contained a $2 \mathrm{~cm}$ yellowish soft nodule with a central necrotic, hemorrhagic focus. In the vaginal segment a nodule of about $1.5 \mathrm{~cm}$ was noticed.

On microscopic examination the tumor nodule was composed of rounded and elongated cells with distinct cell membranes. The nuclei were pleomorphic with clumped chromatin. Multinucleated cells and giant nuclei were rare. The mitotic index was 9 mitoses per $10 \mathrm{hpf}$. Areas of necrosis and fibrinoid material were observed.

The cells were positive for broad spectrum keratin and human placental lactogen as determined by the immunoperoxidase method on formalin fixed, paraffin embedded tissue. The endometrium showed inactive glands.

Microscopic examination of the vaginal metastases revealed relatively few intermediate trophoblastic cells. The majority of the tumor cells were of the syncytial-trophoblastic type with some mitotic activity.

The lung specimen consisted of a fragment of $6 \times 3 \times 1,5 \mathrm{~cm}$ with intact pleura. On cut section the lung parenchyma was replaced by a yellowish soft granular tumor. Histologically this metastasis was composed of rounded and elongated atypical intermediate trophoblastic cells.

Immunohistochemical analyses of the primary tumor showed as in the first case a strong diffuse positivity for cytokeratin (wide spectrum) and a weak positivity for CK 20 and EMA. Reactivity for hCG was rare, whereas reactivity for hPL predominated (Fig. 4).

After treatment with methotrexate the serum hCG level became normal.

A vaginal recurrence measuring $1.8 \times 1.5 \times 0.5 \mathrm{~cm}$ occured 6 months later.
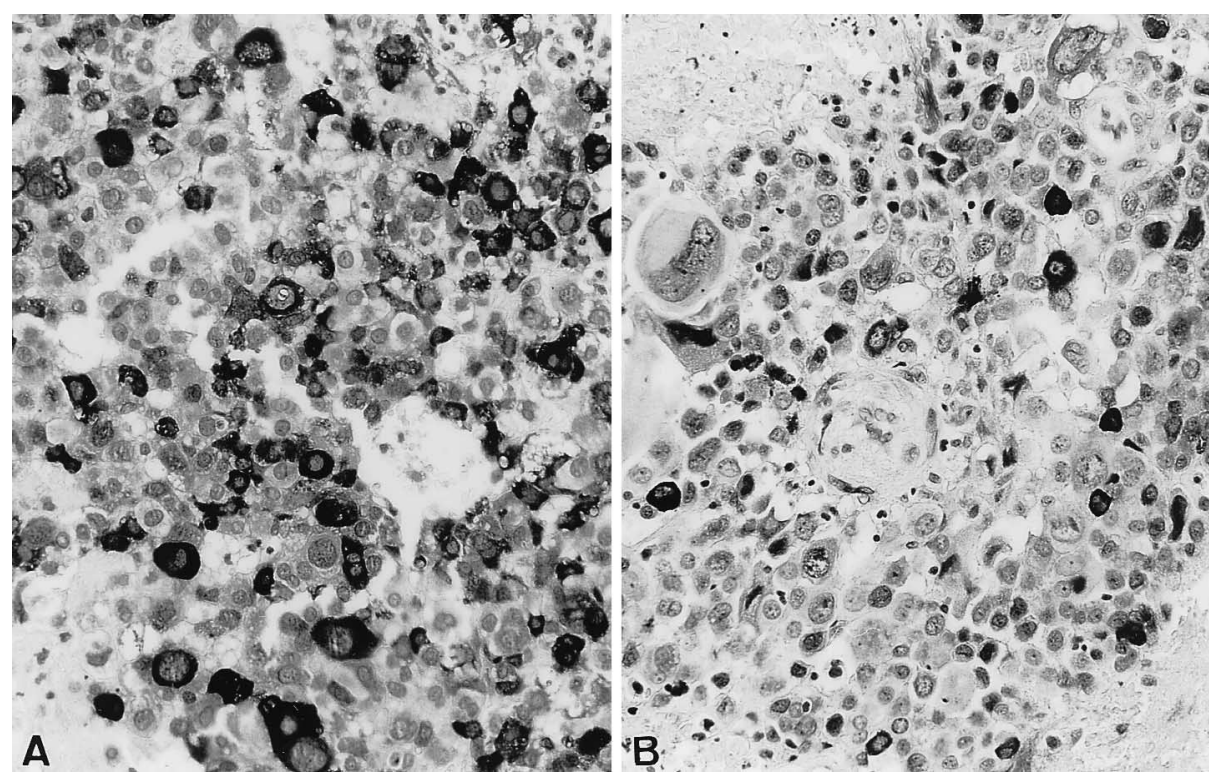

Fig. 4. Case 2: hPL reactive cells (A) are predominant when compared with hCG reactive cells

(B). (Immunoperoxidase $\times 300$ ) 
Twelve months after that the patient presented with pulmonary metastases. EMA-Co chemotherapy was administred and she achieved a short complete remission. Nevertheless the disease progresses and debulking of a cystic lung tumor was carried out. The patient died 5 years after the original diagnosis. No autopsy was performed.

\section{Material and methods}

Curettings from the case 1 and tissue from the uterine lesion in the case 2 were fixed in $10 \%$ neutral buffered formalin, embedded in paraffin, and processed for light microscopy. Formalin-fixed, paraffin-embedded sections were also evaluated immunohistochemically with the avidin-biotin peroxidase complex technique using the following antibodies: cytokeratin (wide spectrum), cytokeratin 20 (1/10, Progen), Vimentin (1/100, Dako), beta human chorionic gonadotropin (1/2000, Dako), human placental lactogen (1/1000, Dako), epithelial membrane antigen (1/100, Dako).

The pulmonary metastatic nodule of case 1 was processed using the same technique as the curettings material, and was evaluated immunohistochemically with the same antibodies. Material for DNA image analysis was available only in the case 1. Tumor cells were stained according the Feulgen method [19]. The instruments were calibrated with the use of lymphocytes on the microscope slide. Tumor cells were individually selected for computerised DNA measurement. Areas of necrosis were excluded. Feulgen concentration was converted by the computer into a measurement of nuclear DNA content.

\section{Discussion}

The PSTT was originally termed "atypical chorioepithelioma" by Marchand in 1895 [16]. In 1976, under the title "trophoblastic pseudotumor of the uterus", Kurman et al. [12] recognized the entity as a form of trophoblastic disease, distinct from choriocarcinoma. Five years later, Scully and Young [21] introduced the term "placental site trophoblastic tumor" to indicate possible malignant behaviour. Since the first report, approximately 90 cases of PSTT have been reported, formerly termed atypical choriocarcinoma [18], chorioepitheliosis [20] or syncytioma [3].

PSTT is a disorder of the reproductive period, occuring at an average age of 28 years [1,17], although several cases have been reported in patients over 50 years of age and in a postmenopausal women [17]. Patients present either with amenorrhea, or with abnormal bleeding, frequently accompanied with progressive uterine enlargment $[1,4]$, suggesting pregnancy.

When the uterine growth ceases, the diagnosis of missed abortion is usually made [12]. PSTT has been diagnosed after term pregnancies, spontaneous abortions, or a prior hydatidiform mole [4, 7, 8, 24].

As PSTT contains little or no syncytiotrophoblast, it is often associated with low serum levels of hCG, typically less than $1000 \mathrm{iu} / \mathrm{l}$. Thus when a sensitive immunologic assay is used, pregnancy tests are always positive, leading to an initial diagnosis of pregnancy [15]. The pathogenesis of PSTT is unclear. The immunohistochemical expression of hPL and hCG in PSTT closely resembles that in the normal intermediate trophoblast, suggesting that PSTT represents a neoplastic transformation of extravillous intermediate trophoblast which is a highly specialized distinctive form of trophoblast $[9,13]$.

PSTT is a neoplasm of capricious and enigmatic behaviour. It can be self-limiting, curable by curettage alone. But 10 to $15 \%$ of cases can follow an agressive course, leading to metastasis and death $[1,4,8,23]$. Including our cases, approximately 21 cases of metastatic PSTT have been reported [17, 21]. Lung metastases have been described only in a few cases $[1,2,5,8,10,17]$. 
In contrast to metastatic choriocarcinoma metastases of PSTT are only occasionally cured by multiagent chemotherapy [10]. Twenty years after the first description of PSTT by Kurman et al. [12], authors are still searching for reliable predictors of outcome in microscopic features, immunohistochemical staining, and DNA analysis $[5,14,22]$.

In our two cases, the mean mitotic rates were respectively 9 and 13 mitotic figures per 10 high-power fields (hpf). Usually the aggressiveness of PSTT correlates with the mitotic count $[4,8]$. In the benign tumors, the mean mitotic count has been $2 / 10 \mathrm{hpf}$, however malignant tumors usually have more than 5 mitotic figures per 10 hpf [6, 7]. In some fatal cases, the mitotic rate was $2 / 10 \mathrm{hpf}$ [7], proving that a low mitotic rate is not an absolute indicator of good prognosis.

As observed in our cases, necrosis is more extensive in the malignant tumors, compared with benign ones limited to the uterus $[2,8,24]$. Pleomorphism and vascular invasion are common features of PSTT, but have no prognostic significance.

Immunohistochemical staining aids the characterization of PSTT and assists in differential diagnosis [14]. In view of their epithelial nature, tumor cells stain intensely with keratin. Typically PSTT shows the reverse staining pattern of choriocarinoma with most tumor cells staining positively for hPL, whereas only few cells stain positively with hCG [14].

hCG immunoreactivity tends to be mainly localized to multinucleate intermediate trophoblastic cells, whereas it is occasionally present in mononucleate IT cells [24]. hCG and hPL production reflect the level of trophoblastic maturation. hPL synthesis indicates a relatively high level of trophoblastic maturation. The more trophoblast cells mature, the less they produce hCG [14].

The percentage of tumor cells stained with hPL was raised in case 2, and relatively low in case 1, when compared with hCG positive cells. We thus agree that the reversed staining pattern cannot always be used as an indicator of poor prognosis $[8,14]$.

Case 1 had an aneuploid tumor with a tetraploid DNA peak and a prominent S-phase fraction. To our knowledge DNA analysis has been done in eight cases of PSTT $[4,5,11]$. In seven of them, the DNA histogram showed a diploid G 1 peak and an S-phase fraction, ranging from $6 \%$ to $24.9 \%$ [4, 5, 11]. Five of these seven patients were alive after a follow-up ranging from 9 months to 11 years, whereas one patient died of multiple lung metastases. The seventh patient had paraaortic lymph nodes and lung metastases, but was alive 15 months after presentation [4, $5,11]$. These finding suggest that DNA ploidy does not give a reliable prognosis.

Acknowledgement. We would like to thank Mrs. M. Lorenz for typing the manuscript and Mrs. M. Redard for immunohistochemical analysis.

\section{References}

1. Eckstein RP, Paradinas FJ, Bagshawe KD (1982) Placental site trophoblastic tumour (trophoblastic pseudotumor): a study of four cases requiring hysterectomy including one fatal case. Histopathology 6:211-226

2. Eckstein RP, Russel P, Friedlander ML, Tattersall MHN, Bradfield A (1985) Metastasizing placental site trophoblastic tumor: a case study. Hum Pathol 16:632-636

3. Ewing J (1910) Chorioma. Surg Gynecol Obstet 10:366-392

4. Finkler NJ, Berkowitz RS, Driscoll SG, Goldstein DP, Bernstein MR (1988). Clinical experience with placental site trophoblastic tumors at the New England trophoblastic disease center. Obstet Gynecol 71:854-857 
5. Fukunaga M, Ushigome S (1993) Malignant trophoblastic tumors: immunohistochemical and flow cytometric comparison of choriocarcinoma and placental site trophoblastic tumors. Hum Pathol 24: 1098-106

6. Gloor E, Hurlimann J (1981) Trophoblastic pseudotumor of the uterus: clinicopathologic report with immunohistochemical and ultrastructural studies. Am J Surg Pathol 5: 5-13

7. Gloor E, Dialdas J, Hurlimann J, Ribolzi J, Barrelet L (1983) Placental site trophoblastic tumor (trophoblastic pseudotumor) of the uterus with metastases and fatal outcome. Clinical and autopsy outcome of a case. Am J Surg Pathol 7:483-486

8. Hopkins M, Nunez C, Murphy JR, Budd Wentz W (1985) Malignant placental site trophoblastic tumor. Obstet Gynecol 66:95S-100S

9. Kabawat SE, Mostoufi-Zadeh M, Driscoll SG, Bhan AK (1985) Implantation site in normal pregnancy, a study with monoclonal antibody. Am J Pathol 118:76-84

10. King LA, Okagaki T, Twiggs LB (1992) Resolution of pulmonary metastases with chemotherapy in a patient with placental site trophoblastic tumor. Int J Gynecol Cancer 2: 328 - 331

11. Kotylo PK, Michael H, Davis TE, Sutton GP, Mark PR, Roth LM (1992) Flow cytometric DNA analysis of placental site trophoblastic tumors. Int J Gynecol Pathol 11:245-252

12. Kurman RJ, Scully RE, Norris HJ (1976) Trophoblastic pseudotumor of the uterus. An exaggerated form of "syncytial endometritis" simulating a malignant tumor. Cancer 38: $1214-1226$

13. Kurman RJ, Main CS, Chen HC (1984) Intermediate trophoblast: a distinctive form of trophoblast with specific morphological, bochemical and functional features. Placenta 5: 349-370

14. Kurman RJ, Young RH, Norris MJ, Main CS, Lawrence WD, Scully RE (1984) Immunocytochemical localization of placental lactogen and chorionic gonadotropin in the normal placenta and trophoblastic tumors, with emphasis on intermediate trophoblast and the placental site trophoblastic tumor. Int J Gynecol Pathol 3: 101-121

15. Kurman RJ (1994) Blaustein's pathology of the female genital tract. 4th ed. Springer Berlin Heidelberg New York, pp 1074-1078

16. Marchand F (1985) Über die sogenannten ,,decidualen“ Geschwülste im Anschluß an normale Geburt, Abort, Blasenmole und extrauterine Schwangerschaft. Monatsschr Geburtshilfe Gynaekol 1:419-438

17. McLellan R, Buscema J, Currie JL, Woodruff JD (1991) Placental site trophoblastic tumor in a postmenopausal woman. Am J Clin Pathol 95:670-675

18. Park WW (1981) Pathology and classification of trophoblastic tumors. In: Coppleson W (ed) Gynaecologic Oncology Churchill-Livingstone, Edinburgh. pp 745-756

19. Pearse AGE (1968) Histochemistry: theoretical and applied 3rd ed. Little, Brown and Co, Boston. pp 254-265

20. Schopper W, Pliess G (1949) Über Chorioepitheliosis. Ein Beitrag zur Genese, Diagnostik und Bewertung ektopischer chorionepitheliarer Wucherungen. Virch Arch Pathol Anat $317: 347-384$

21. Scully RE, Young RH (1981) Trophoblastic pseudotumor. A Reappraisal. Am J Surg Pathol 5:75-76

22. Silverberg S, Kurman RJ (1991) Tumors of the uterine corpus and gestational trophoblastic disease. Armed Forces Institute of Pathology, Washington DC

23. Twiggs LB, Okagaki T, Phillips GL, Stroemer JR, Adcock LL (1981) Trophoblastic pseudotumor. Evidence of malignant disease potential. Gynecol Oncol 12:238-248

24. Young RH, Scully RE (1984) Placental-site trophoblastic tumor: current status. Clin Obstet Gynecol 27: 248-258 